\section{An Oncologist's Letter to Santa: Bring Me Drugs!}

\author{
Dear Santa,
}

Greetings from JNCCN! I hope things are going well at the North Pole. I imagine you and your elves are busy as bees right now. And I suspect Mrs. Claus is hard at work making Christmas cookies and candy. Just a reminder — sugar isn't so good for you, so you might want to cut back and eat some broccoli instead.

I've been a really good girl this year, so I'm hoping you can come through on my Christmas wish list. I admit, last time I wrote, I was pretty disappointed you couldn't fix HIPAA, but I did appreciate your letter of explanation. And the Jimmy Choo shoes you sent were awesome. Unfortunately, I had a knee replacement and I can't wear them anymore, but they sure look great on the shoe shelf!

This year, I need some drugs, but not just any drugs. I need the drugs that aren't being made anymore. For example, right now, we are running out of intravenous diphenhydramine. In case you don't know this drug, it is very useful when you are having a bad allergic reaction, especially if you can't swallow a pill. In fact, it's a basic medical necessity. Over the years, we have had shortages of lots of drugs that patients with cancer need, especially lifesaving chemotherapy drugs!

Now, given your focus on toys and other luxuries, you might not understand how we could run short of something like this. You see, when a new drug is invented, it is protected by a patent, and the drug company always makes lots of it to sell so they can make money. But the patent only lasts 20 years, and after that anyone can make the drug. These are called generic drugs, and having them available usually means the drug must sell for less. Most of the time this works out okay, and somebody steps up and makes what we need. But some companies decide that it isn't worthwhile to make certain drugs or formulations and they stop—just like that. Can you imagine?

The problem is that no one has any authority to force a company to make drugs. The FDA looks after drug safety. They advise us when they think a shortage is likely, but they can't do anything in advance to keep the drugs in production.

I'm kind of thinking you could set up production at the North Pole. I mean, if you can make fancy bikes and stuff, why can't you do this? It's worth thinking about. The FDA could just send you emails when they think things are going to be a problem and then-"Abracadabra!"-you could have it done.

In the meantime, I hope you are not allergic to anything. If you are, you might think about keeping some diphenhydramine in pill form in your Santa sack just in case. If you think you are having a reaction, take it while you're on the way to the emergency department, since they won't have any intravenous drug when you get there. It does make you sleepy, so have an elf ride shotgun and give him the reins so you don't confuse the reindeer or crash the sleigh. That would be very bad.

Well, Santa, thanks for considering my request. I know you have a lot on your plate, but you always seem to pull a rabbit out of a hat. I don't know how you do it. You're the best!

Happy Holidays and safe travels!

$$
\text { Love, }
$$

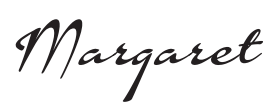

What do you think? E-mail correspondence (include contact information) to JNCCN@nccn.org or log into www.editiorialmanager.com/JNCCN to submit a Letter to the Editor.

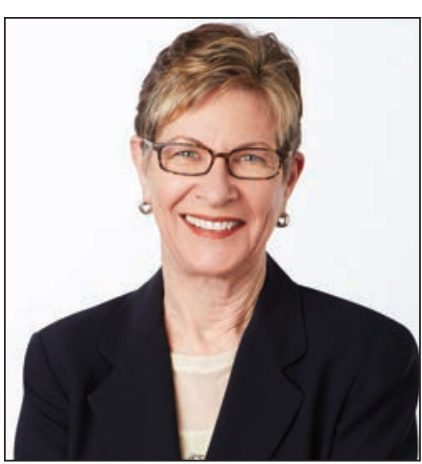

Margaret Tempero, MD

Margaret Tempero, MD, is a Professor of Medicine and Director of the UCSF Pancreas Center and editor-in-chief of JNCCN. Her research career has focused on pancreatic ductal adenocarcinoma, especially in the area of investigational therapeutics. Dr. Tempero has served on the ASCO Board of Directors and as ASCO President. She currently serves on the ASCO Conquer Cancer Foundation Board. She codirected the AACR/ASCO Methods in Clinical Cancer Research and taught this course and similar courses in Europe and Australia. She was founding Chair of the $\mathrm{NCl}$ Clinical Oncology Study Section and served as a member and Chair of the NCl Board of Scientific Counselors Subcommittee A. She is a member of the Scientific Steering Committee and Chair of the Clinical and Translational Study Section for the Cancer Prevention \& Research Institute of Texas. She is or has been on the Scientific Advisory Boards of the Lustgarten Foundation, the Pancreatic Cancer Action Network, the $V$ Foundation, The Alberta Canada Cancer Board, and the EORTC. She served as a member of the Oncology Drug Advisory Committee for the FDA. She has served as Deputy Director and Interim Director for the UNMC Eppley Cancer Center. She is Chief Emeritus of the Division of Medical Oncology at UCSF and served as the founding Deputy Director and Director of Research Programs at the UCSF Helen Diller Family Comprehensive Cancer Center.

doi: 10.6004/jnccn.2018.0090

The ideas and viewpoints expressed in this editorial are those of the author and do not necessarily represent any policy, position, or program of NCCN. 